Review Article

\title{
THE RESEARCH UPDATES AND PROSPECTS OF HERBAL HARD-BOILED LOZENGES: A CLASSICAL PLATFORM WITH PROMISING DRUG DELIVERY POTENTIAL
}

\section{MANAS RANJAN SAHO0 ${ }^{1}$, MARAKANAM SRINIVASAN UMASHANKAR ${ }^{1}$, RAMESH RAGHAVA VARIER ${ }^{2}$}

${ }^{1}$ Department of Pharmaceutics, SRM College of Pharmacy, SRM Institute of Science and Technology, Kattankulathur, Tamilnadu, India, 603203, 2AVN Ayurveda Formulation Pvt Ltd, Madurai, Tamilnadu, India, 625004

Email: umashankarms.umashankar1@gmail.com

Received: 03 Nov 2020, Revised and Accepted: 05 Jan 2021

\begin{abstract}
Over the past decades major focus has been given towards innovative drug delivery systems and new dosage forms. This is due to highly expensive process and high attrition rates of existing marketed drugs. Hard-boiled lozenges (HBLs) are one of the solid dosage form designed to release the drug in saliva for either local or systemic effects. Typical application of lozenegs includes throat infection, pharyngitis, cough suppressant, nasaldecongestant, expectorants, and smoking cessation. The drug delivery through the hard-boiled candies has an easy marketing advantage due to its attractive appearance and patient compliance. As a part of the drug is absosrbed into systemic circulation, gastrointestinal degradation and fast pass effects are avoided. Further, drug delivery through hard-boiled lozenges can be potential platform for some of the suitable drug candidates. This review on hard-boiled lozenges discusses manufacturing process, characterization techniques, quality control, research studies and market potential of hard-boiled lozenges. The major databases searched were, PubMed, Wiley Online, Medline, Elsevier, Google scholar, Scopus, ACS, The Royal Society of Chemistry, SciFinder, Baidu Scholars, CNKI, web of science, Cochrane database, US Patents, Espacenet and various business reviews. This review provides comprehensive information on hard-boiled lozenges that will help the pharmaceutical scientist from academia as well pharmaceutical industry to leverage the potential of this conventional dosage form for various herbal drugs and other pharmaceutical actives.
\end{abstract}

Keywords: Medicated hard-boiled lozenges, Herbal drug, Drug delivery, Dosage form, Formulation, Characterization

(C) 2021 The Authors. Published by Innovare Academic Sciences Pvt Ltd. This is an open access article under the CC BY license (https://creativecommons.org/licenses/by/4.0/) DOI: https://dx.doi.org/10.22159/ijap.2021v13i2.40165. Journal homepage: https://innovareacademics.in/journals/index.php/ijap

\section{INTRODUCTION}

The drug administration through the oral route is one of the most widely used and preferred way of drug delivery due to its several advantages such as safety, ease of administration, non-invasiveness, better patient compliance, acceptability and simplicity [1]. It has been estimated that out of the current marketed oral pharmaceutical constitutes largest portion pharmaceutical products of $62.02 \%$, followed parenteral $(22.43 \%)$, other route of drug delivery such as topical route $(8.70 \%)$, mucosal drug delivery $(5.22 \%)$, inhalation dosage form (1.21\%) and others $(0.42 \%)$ [2]. The results indicate that oral cavity is the most convenient site for administration of both locally and systemically acting drugs. The oral dosage form consists of both solid and liquid dosage forms, considered to be the first choice of drug delivery system for a newly developed drug due to flexibility in its formulation design. Solid oral dosage forms includes popular formats such as tablets, capsules and other dosage forms like powders, granules, fast dissolving tablets, oral dispersible films, while liquid oral dosage forms consist of syrups, drops, sprays, solutions, emulsion, suspension, dispersions, semisolids and soft gels [3-5]. There has been a numerous research work done in the field of various oral dosage forms. Regarding application of hard boiled lozeneges in drug delivery, to the best of our knowledge, there is no comprehensive review article published exploring this specific dosage form. So in this attempt this review will focus on research work and significance of hard boiled lozenges (HBL) as a solid dosage form for drug delivery.

Lozenges are defined as flavoured solid unit-dosage form of drug delivery usually designed to hold in oral cavity and wetted with saliva and slowly dissolved until complete dissolution. It is used both for local action of drugs in the mouth and pharynx for sore throat or pharyngitis and for systemic action such as pain relief and antacid. The lozenges are defined as hard solid, unit-dosage forms intended to slowly dissolve or disintegrate in the oral cavity [6-9]. There are several types of lozenges such as chewy, caramel, compressed tablet lozenges, soft lozenges, hard boiled lozenges classified on the basis of texture and composition $[10,11]$. The hard lozenges are either sugar based or sugar-free formulations introduced around the year 1970. Hard boiled lozenges (HBL) also known as Hard Boiled Candies (HBC) represents the most common and popular products within consumers. A typical hard boiled lozenge is 2 to $3 \mathrm{~g}$ in weight with a diverse size, shape, colour and flavours. These are generally made from hydrophilic water soluble substances such as sucrose, dextrose, liquid glucose or sugar free and low calorie based materials like isomalt, sorbitol or mannitol $[12,13]$.

\section{Advantages of hard boiled lozenges}

The administration of the hard boiled lozenges has better consumer preference due to their great taste, aroma, flavour, and elegant appearance with attractive colours. Further flavoured and sweetened lozenges help in masking bitter and unpleasant taste of active drugs substance. It has good acceptance among patients having difficulty in swallowing. It is safe to administer with ease of accessibility and removal. For taking lozenges it does not need additional water for administration and can be taken anywhere. As it is made up of highly hydrophilic materials such as sugar, liquid glucose or isomalt it gets dissolved easily which leads to quick onset of action. Further large surface area of oral cavity helps in rapid disintegration and dissolution. In addition, high blood supply and permeability of oral mucosa leads to quick absorption and rapid onset of action [13,14]. As part of drug absorption from lozenges takes place directly in buccal mucosa it provides better metabolic and enzymatic stability to the drug and also reduces extent of gastric irritation. Further there is a less drug metabolism in buccal cavity due to reduced enzymatic activity of peptidase and protease [15]. The manufacturing process of HBL is a simple and easy with limited steps, less number of excipients, least expensive and solvent free process.

However, the hard-boiled medicated lozenges are also having certain disadvantages like it might be appreciated by children as a confectionary so should be restricted from their access. There is a risk of choking and aspiration [15]. Due to high processing temperature during candy preparation thermolabile active ingredients are not stable in HBL formulation due to chances of their degradation and hydrolysis. The base used in the product manufacture should be having better flow properties. The drug should be having suitable physicochemical properties such as better solubility in saliva, and should be non-irritant on buccal mucosa. As continuous secretion of saliva is required for dissolving, it is not 
suitable for patients having dry mouth syndrome with insufficient saliva. Sucking of acidic candies has also been reported to have erosive potential in mouth and cause gastrointestinal disturbances. It has been reported that excess consumption of isomalt is reported to cause laxative effect [16-18]. Frequent use of fentanyl citrate containing sucrose-based lozenges has been reported to cause severe dental caries [19]. A conventional lozenge initially releases the drug at higher rate that declines rapidly to below therapeutic label that leads to systemic toxicity and compliance [20]. As the menthol-based lozenges available as over-the-counter (OTC) medicines may worsen the severity of cough due to overuse [21].

Some of the zinc lozenges have been reported with adverse effects like acute bad taste, which is commonly found to be reversed after discontinue of taking the same [22]. Potential drug interaction has been suspected between the common ingredients found in the cough drops such as eucalyptus oil, menthol and licorice with warferin due to their affinity towards cytochrome P450 and their ability to bind with albumin [23]. Moreover, other limitation are the comparatively small surface area available for drug absorption, shorter residence time of the dosage form in oral cavity due to simultaneous swallowing of drug with saliva.

\section{Challenges in bioavailability}

Poor oral bioavailability of new chemical entities (NCEs) continues to be the major obstacle against development of new drug formulation due to poor aqueous solubility. It has estimated that more than $40 \%$ of approved drug molecules developed from the process of drug discovery and $70 \%$ of drug molecules in development pipeline qualified as biopharmaceutical classification systems (BCS) class-II and Class IV. Low solubility of drugs candidates lead to poor bioavailability, inefficient formulation or attrition and failure from the developmental pipeline, which make an increase in cost of drug development for the inventors [24-27]. Many herbal-based drugs and extracts having excellent in vitro activity showed poor action in preclinical and clinical-stage due to their poor aqueous solubility. These remain as major obstacle in the developability of many botanicals and herbal extracts into suitable dosage forms [28].

Table 1: List of some marketed lozenges

\begin{tabular}{|c|c|c|c|c|}
\hline S. No. & Trade name & Active Ingredient & Developer & Indication \\
\hline 1. & Drill $^{\circledR}$ & $\begin{array}{l}\text { Chlorhexidine-digluconate, tetracaine } \\
\text { hydrochloride }\end{array}$ & Pierre Fabre-France & $\begin{array}{l}\text { Cough relief } \\
\text { antimicrobial and antiviral }\end{array}$ \\
\hline 2. & $\begin{array}{l}\text { Horehound } \\
\text { lozenges }\end{array}$ & Marrubiumvulgare & & Cough relief \\
\hline 3. & Halls & Menthole, eucalyptus oil, hexylresorcino & $\begin{array}{l}\text { Mondelez } \\
\text { International } \\
\text { Cadbury-USA }\end{array}$ & Antitussive, natural cough suppressant \\
\hline 4. & $\begin{array}{l}\text { VICKS }^{\circledR} \text { cough } \\
\text { drops }\end{array}$ & Menthol & $\begin{array}{l}\text { Procter and Gamble- } \\
\text { USA }\end{array}$ & $\begin{array}{l}\text { Antitussive: Throat lozenge for cough and } \\
\text { sore throat-cough suppressant and oral }\end{array}$ \\
\hline 5. & $\begin{array}{l}\text { ZICAM cold } \\
\text { remedy }\end{array}$ & Zinc acetate, zinc gluconate and menthol & & $\begin{array}{l}\text { Cold, flu and allergies, to treat or reduce } \\
\text { symptoms of the cold virus. }\end{array}$ \\
\hline 6. & Strepsils & $\begin{array}{l}\text { 2,4-dichlorobenzyl alcohol, amylmetacresol, } \\
\text { hexylresorcinol, flurbiprofen }\end{array}$ & Reckitt Benckiser-UK & $\begin{array}{l}\text { Sore throat, viral infection, anti- } \\
\text { inflammatory actions, antiseptic, upper } \\
\text { respiratory tract infection, analgesic. }\end{array}$ \\
\hline 7. & Dorithricin & $\begin{array}{l}\text { Tyrothricin, benzalconium chloride, and } \\
\text { banzocaine }\end{array}$ & $\begin{array}{l}\text { MEDICE Arzneimittel } \\
\text { Pütter GmbH and Co. } \\
\text { KG, Germany }\end{array}$ & $\begin{array}{l}\text { Throat pain, acute pharyngitis and sore } \\
\text { throat, antiviral. }\end{array}$ \\
\hline 8. & Koflet & Ginger, pepper, clove, licorice & $\begin{array}{l}\text { Himalaya Drug } \\
\text { company-India }\end{array}$ & $\begin{array}{l}\text { Pharyngitis, Laryngitis, respiratory tract } \\
\text { disease }\end{array}$ \\
\hline 9. & Hajmola & $\begin{array}{l}\text { Combination of digestive herbals extracts } \\
\text { and powder }\end{array}$ & Dabur-India & Digestive \\
\hline 10. & Bronchipret & $\begin{array}{l}\text { Thymus vulgaris), ivy (Hedera helix) or } \\
\text { cowslip (Primula veris) }\end{array}$ & Bionorica-Germany & $\begin{array}{l}\text { Common cold, respiratory inflammation } \\
\text { and bronchitis }\end{array}$ \\
\hline 11. & NT tuss & $\begin{array}{l}\text { Holy basil, turmeric, licorice, galangal, } \\
\text { Vasaka }\end{array}$ & Cadila Pharma & Sore throat and cough \\
\hline 12. & $\begin{array}{l}\text { Golden Throat } \\
\text { Lozenge }\end{array}$ & $\begin{array}{l}\text { Honey Suckle Flower (jin yin hua), } \\
\text { Peppermint Oil, Eucalyptus Oil, Luo-Han- } \\
\text { GuoFruit, Tangerine Peel (juhong),Star } \\
\text { Anise Oil,Sucrose }\end{array}$ & $\begin{array}{l}\text { Solstice medicine } \\
\text { company }\end{array}$ & $\begin{array}{l}\text { Sore throat, halitosis and upper respiratory } \\
\text { tract discomfort }\end{array}$ \\
\hline 13. & Devilion & Caffeine and taurine & Devilion Energy & Energy and sports \\
\hline 14. & ViraBLOC@ & Elderberry extract & GNC & Upper respiratory tract infections. \\
\hline 15. & $\begin{array}{l}\text { Sambucus } \\
\text { Immune } \\
\text { Lozenge }\end{array}$ & $\begin{array}{l}\text { Elder berry extract, Vitamic C, Zinc } \\
\text { gluconate }\end{array}$ & Nature's Way & Immune support \\
\hline 16. & $\begin{array}{l}\text { Benadryl-DR } \\
\text { cough lozenges }\end{array}$ & Dextromethorphan Hydrobromide & Johnson and Johnson & Dry cough and throat irritation \\
\hline 17. & $\begin{array}{l}\text { Strepsils } \\
\text { Intensive }\end{array}$ & Flurbiprofen & Reckitt Benckiser & Pain relief from sore throat \\
\hline 18. & Andolex-C & $\begin{array}{l}\text { Benzydamine-hydrochloride, } \\
\text { Cetylpyridinium chloride }\end{array}$ & $\begin{array}{l}\text { iNOVA } \\
\text { Pharmaceuticals }\end{array}$ & Pain and inflammation in the throat \\
\hline 19. & Cepacol & Menthol and Benzocaine & Adcock Ingram & Sore throat and throat pain \\
\hline 20. & Medi-Keel A & cetylpyridinium chloride, benzocaine & Adcock Ingram & Sore throat \\
\hline 21. & $\begin{array}{l}\text { Goldex throat } \\
\text { lollies }\end{array}$ & Cetylpyridinium Chloride & Goldex healthcare & Sore throat, tonsilitis, laryngitis \\
\hline 22. & $\begin{array}{l}\text { EpiCor® Throat } \\
\text { Lozenges }\end{array}$ & $\begin{array}{l}\text { Saccharomyces cerevisiae extract, menthol, } \\
\text { manuka honey }\end{array}$ & $\begin{array}{l}\text { Embria Health } \\
\text { Sciences, LLC }\end{array}$ & Immune support \\
\hline 23. & AllergEase & $\begin{array}{l}\text { Nettle, eyebright, elderflower, plantain, } \\
\text { vitamin } \mathrm{C} \text {, and menthol }\end{array}$ & AllergEase LLC & Seasonal allergies, immune supports \\
\hline 24. & PhytoRelief-CC & $\begin{array}{l}\text { Contains Turmeric, Pomegranate and } \\
\text { Ginger }\end{array}$ & Alchemlife & Cold, Flu and immune health. \\
\hline
\end{tabular}


Some of the examples are bioactive molecules of natural origin for example, oleanolic acid, artemether, piperine, quercetin and andrographolide that have poor bioavailability due to low water solubility and high first-pass metabolism [29-31]. As discovery and development of new chemical entities or new molecular entities (NCEs/NMEs) is a very complex, difficult, expensive and timeconsuming process, there is need of advanced or novel drug delivery technology for the drug candidates with poor bioavailability [3]. This will reduce the high attrition of molecules from the developmental pipeline resulting in success and value creation for innovators [27]. Therefore, there is an urgent need to develop alternative formulations that will enhance solubility, bioavailability, taste masking and patient compliance. The commonly used drug delivery strategies to enhance the solubility of low polar drugs are making salt forms of drugs, use of co-solvents, drug-complexes, liposomal drug delivery, micronization, microemulsion, and solid dispersion [31]. Hard-boiled lozenges (HBL), which are made by homogenous mixing of the drug in the sugar-based or sugar-free molten base, may be a potential solution for development of formulation with improved solubility for thermo-stable drugs with high melting point and poor water solubility. In HBL the drug is dispersed in molten base by molecular mixing to make amorphous solid dispersion.

\section{Current business review on hard-boiled candies}

Hard boiled lozenges with innovative taste, texture, attractive colours, flavours, aromas and functional benefits are gaining popularity in the nutraceutical and pharmaceutical market. Some of the leading Indian and global players in the hard lozenges segments are DS group, Cadbury, Nestle, Unilever, Procter and Gamble, Parry's, Nutrine. Inbisco, Mondelez, Perfetti-Van-Melle, Ferrara Candy, Haribo, and Wrigley. The market value of hard-boiled-lozenges in India is estimated at around $\$ 1.3$ billion reported as per express financial news in 2018. According to Nielsen market insight data, in India hard boiled lozenges is growing by $24 \%$ year to year. According to Technavio report the hard-boiled lozenges is having a global market of $\$ 1.6 \mathrm{bn}$. In the USA horehound-based lozenges are top-selling herbal supplements used for sore throat with market share of $\$ 115$ million in sales in year 2015. In recent years for product line extension, generic lozenge-based products have become an alternative option. It helps in enhancing the attractiveness of an existing product by providing appealing appearance and helps in positioning high-boiled lozenges as a strong and unique selling point different from their competitors [32]. List of some of the medicated lozenges is given in below table 1 .

\section{Research work on the allopathic lozenges}

Several research articles have been published for various allopathic drug molecules, including efficacy, clinical study, absorption, bioavailability, compatibility, composition and physicochemical evaluation in the form of hard-boiled lozenges. Some of the most notable studies deals with cough drops that contains antimicrobials such as amylmetacresol, 2,4-dichlorobenzyl alcohol, hexylresorcinol, chlorohexidine, tetracycline, and benzalkonium chloride, local anaesthetic such as benzocaine, pain killers like non-steroidal antiinflammatory drugs (NSAIDs) and immunity minerals such as Zinc. A brief highlights of some of the research outcomes are briefed below.

\section{Amylmetacresol, 2,4-dichlorobenzyl alcohol and hexylresorcinol lozenges}

Lozenges containing amyl meta cresol, 2,4-dichlorobenzyl alcohol and hexylresorcinol have been shown to provide relief from sore throat. In vitro studies have shown their anti-viral effects in influenza A, cytomegalovirus, respiratory synctial virus (RSV) and severe acute respiratory syndrome coronavirus (SARS-CoV) that causes respiratory tract infections. These compounds have also been reported for the antibacterial, local anaesthetic and pain relief activity in sore throat. These activities substantiate the usage of these lozenges for sore throat due to viral respiratory tract infections. So these lozenges can be used by patients to avoid unnecessary usage of antibiotics [33-35]. The efficacy of lozenges containing combination of amylmetacresol and 2,4-dichlorobenzyl alcohol was clinically investigated through a multicentre, randomised, double-blind, single-dose study on 225 subjects. The lozenges exhibit analgesic and local anesthetic effects in the treatment group as compared to that of the controlled group. The results suggest that lozenges were well-tolerated and effective and alternative treatment option for sore throat as OTC medicines [36].

\section{Amphotericin lozenges}

Amphotericin lozenges have been found to be effective in the treatment of oropharynx with candida infection [38]. In a clinical study on 14 patients having haematological malignancies, pharmacokinetic study was done with amphotericin lozenges containing $10 \mathrm{mg}$ of drug. The lozenges were taken 3 to 4 times a day by the patients. Pharmacokinetic study showed that indicates that systemic absorption of amphotericin increased 10 to 50 times in contrast to its conventional formulations. It was observed that 8.3 To $9.9 \%$ of drug was absorbed from lozenges formulation as compared to its conventional dosage form in which absorption is 0.2 to $0.9 \%$ from a much higher dose of $2-10 \mathrm{~g} /$ day [37].

\section{Clotrimazole lozenges}

The compatibility and physicochemical evaluation of clotrimazole in isomalt and liquid glucose based lozenges designed for paediatric oral thrush. The FTIR studies indicate no interaction between drug and excipient and are compatible with each other. Further stability studies have confirmed that its stability over a period of seven weeks under $45^{\circ} \mathrm{C}$ and $75 \%$ relative humidity condition [39].

\section{Albendazole lozenges}

Compatibility of albendazole in lozenges formulation prepared from sucrose, dextrose and sorbitol has been studied. The fourier transform infrared (FTIR) studies revealed the compatibility of the albendazole and the lozenegs base without any drug-excipient interactions. Further stability data confirms the stability of formulation [40].

\section{Ketoconazole lozenges}

Compatibility of ketoconazole based lozenges has been studied in sugar, liquid glucose-based hard boiled lozenges and found to be stable and compatible without any drug-excipient interactions from FTIR study. Ketoconazole lozenges have been found to be an attractive alternative formulation in the treatment of oral thrush pediatric population clinical trial [41].

\section{Chlorohexidine and tetracycline lozenges}

A lozenge containing $3 \mathrm{mg}$ of chlorohexidine and $0.2 \mathrm{mg}$ of tetracycline per lozenge known as Drill ${ }^{\circ}$ has been proven to show antibacterial and antiviral activity in vitro antimicrobial assay of $S$. aureus, S. pneumoniae, S. pyogenes, H. influenzae, B. catarrhalis and H1N1 virus. These in vitro tests substantiate the use of this lozenge in the treatment of upper respiratory tract infections such as sore throat [42].

\section{Tyrothricin, benzalkonium chloride and benzocaine lozenges}

Benzocaine, benzalkonium chloride and tyrothricin are having local anaesthetic, analgesic and broad spectrum antimicrobial activity. A clinical study was conducted with marketed lozenges, Dorithricin ${ }^{\circledR}$ containing above three actives on 160 subjects with acute phrayngitis. The clinical results exhibited significant analgesic effect in throat pain relief. This indicates dothricine could be a better treatment method for management of acute pharyngitis and sore throat [43].

\section{Zinc lozenges}

Zinc lozeneges has been found to be beneficial in reducing the duration and severity of the symptoms related to common cold due to its antiviral activity zin ion against rhinovirus and immune boosting activity. Zinc is used in the form of zinc acetate, zinc gluconate and zinc citrate. The mechanism of action being increase in interferon-gamma (IFN-gamma) and inhibition of intercellular adhesion molecule-1 (ICAM-1) and stabilization of mast cell [44-48]

\section{Salbutamol lozenges}

Salbutamol sulphate based hard lozenges prepared from Isomalt and combination of isomalt and liquid glucose exhibits good physical 
properties and showed delayed drug release profile for $60 \mathrm{~min}$. The stability was confirmed on basis of a seven weeks stability studies without any drug and excipients interaction [7].

\section{Hydrochlorothiazide lozenges}

The bioavailability of hydrochlorothiazide from isomalt-moulded tablets and lozenges has been evaluated in healthy volunteers after oral administration of $50 \mathrm{mg}$ dose of each of the formulation. The lozenges formulation of hydrochlorothiazide found to show improvement in bioavailability as compared to conventional tablet formulation. Superior bioavailability mainly attributed due to the lozeneges formulation that improves oral dissolution and bioavailability [49].

\section{Nimesulide lozenges}

Nimesulide is an analgesic and antipyretic drug used for fever and body pain. Hard candy-based medicated lozenges has been prepared and found to be having satisfactory parameters such as hardness, content uniformity, weight variation, dissolution rate and compatibility study was carried out for all lozenges formulation. The in vitro dissolution study showed $97.62 \%$ drug release in $30 \mathrm{~min}$ [50].

\section{Ascorbic acid lozenges}

Akansha et al. has developed the hard candy lozenges made up of sugar base. The preformulation study various polymer such as methylcellulose, locust bean gum, HPMC, K4M and xanthan gum was used for controlling dissolution rate of the lozenges. The Formulation was found to be having satisfactory stability-indicating the lozenges format could be an attractive dosage form for the administration of ascorbic acid through oral route [51]

\section{Probiotic lozenges}

Probiotic bacteria such as Lactobacillus brevis and Lactobacillus reuteri are commonly known as good bacteria of human origin. Clinical trials on children with plaque and bleeding have shown that Lactobacillus brevis CD2 (Inersan ${ }^{\circledR}$ ) lozenges improve oral health by inhibiting growth and adhesion of cariogenic bacteria like Streptococcus mutans. Another clinical trial has shown that lozenges of Lactobacillus brevis CD2 is effective in treatment of recurrent aphthous stomatitis with improvement in painful ulcers in tonsils, palates, pharynx, or tongue area of mouth. Sucking of probiotic lozenges containing Streptococcus salivarius and Lactobacillus reuteri have been found to be effective in relief of gingivitis, periodontitis and improvement of plaques and gum bleeding [52-55].

\section{Research studies on herbal lozenges}

Several research studies have been published on various compositions of medicated hard-lozenges. An experimental clinical trial of essential oil-based lozenges that contain lavender essential oil, hop extract and lemon balm essential oil has been found to exert antidepressant effect. These ingredient acts through modulation of electrophysiology in brain [56]. Another clinical trial of effect of polyherbal lozeneges for relief of cough on children in comparison with acefyllin, aminophylline and diphenhydramine group found to be better with lesser side effects [57]. Sugar free lollipop prepared from glucyyrrhizol containing licorice extracts has been developed to prevent dental caries and has been proven in human trials. It acts through its antimicrobial effects on cariogenic bacteria Streptococcus mutans. This herbal lollipop could be a novel tool to promote oral health through functional foods [58-61]. Lozenges have been developed consisting of extracts of spices, ginger and garlic. The lozenges were found to be having anti-fungal through suppression of pathogenic fungus Candia albicans. This study indicates that lozenges can be used for non-resistant oral candidiasis.

\section{Trans-resveratrol lozenges}

Resveratrol, which is obtained mostly from grapes, is well known for its activities in atherosclerosis, diabetes, immune disorders, cancer and inflammatory diseases. Chemically, it is a polyphenol with limited bioavailability when delivered through oral route. This is accounted for its poor solubility in water and extensive metabolism in the small intestine and liver. To overcome its poor bioavailability resveratrol was administered through the buccal cavity as lozenges and it has been found to increase the bioavailability of resveratrol. These lozenges dissolve in mouth and enhance the absorption of the resveratrol as it is not entering the small intestine or liver where it is extensively metabolized. The onset of action was also faster when compared to the tablets, capsules or powders of resveratrol. In a clinical trial conducted on two healthy volunteers resulted in better pharmacokinetic properties using lozenges. Lozenges of resveratrol prepared using ribose, fructose and sucrose having approximately $146 \mathrm{mg}$ of resveratrol resulted in higher $\mathrm{C}_{\max }$ and faster $\mathrm{T}_{\max }$ compared to conventional dosage forms that are absorbed though the gastrointestinal tract. Cmax and Tmax for trans-resveratrol were 325 and $332 \mathrm{ng} / \mathrm{ml}$ after $15 \mathrm{~min}$ in the two healthy volunteers studied. On the contrary, conventional oral dosage resulted in 25 $\mathrm{ng} / \mathrm{ml}$ after $48 \mathrm{~min}$ and $43.8 \mathrm{ng} / \mathrm{ml}$ after one hour in the two healthy volunteers. Hence, the lozenges of resveratrol were proved to be better than the other conventional oral dosage forms like tablets and capsules that are intended to be absorbed from the intestine [62].

\section{Curcumin lozenges}

Vinay et al. have evaluated effects of curcumin lozeneges and $0.05 \%$ of clobetasol propionate ointment in a randomized clinical trial done on 30 patients diagnosed with oral submucous fibrosis (OSF), equally divided into two groups. The results showed that curcumin lozenges exhibited better effect as compared to $0.05 \%$ of clobetasol propionate ointment in treatment of OSF [63].

\section{Echinacea purpurea lozenges}

Echinacea purpurea is a popular herb traditionally used in the treatment of common cold and upper respiratory tract infections. Dodeca-2E, 4E, 8Z, 10E/Z-tetranoic acid isobutylamide is one of the active constituents of the herb. The bioavailability of active metabolite performed on healthy human volunteers showed that the active constituent appeared quicker than the conventional dosage forms while using lozenges. Using LC-MS it was found that the active metabolite alkamide was detected within $10 \mathrm{~min}$ for 0.21 and $0.9 \mathrm{mg}$ dose and at $20 \mathrm{~min}$ for $0.07 \mathrm{mg}$ lozenges. This rapid appearance of active metabolite in blood indicates the faster action of the active constituent. It was also found that the pro-inflammatory markers such as IL-12p70, IL-8, IL-6, IL-10 and TNF were inhibited within 24 $\mathrm{h}$ of lozenge administration which indicate the improvement in the performance of the active constituent [64-67].

\section{Cyanidin lozenges}

It has been observed that the bioavailability of cyanidinetaken as drink is approximately $0.2 \%$ and while cyanidine administered in the lozenge form has bioavailability of $20 \%$ based on a LC-MS based analysis of serumand urine sample. Therefore, lozenge form could be preferred administration mode for cyanidin administration [68].

\section{Elderberry lozenges}

From centuries Elderberry (Sambucus nigra) has been used in traditional medicine for treatment of cold, flu, influenza and sinusitis. Further clinical trial and in vitro study has reported extract of Elderberry against antiviral activity such as influenza-A and B and herpes simplex infection, and anti-bacterial activities against respiratory pathogenic bacteria such as Streptococcus pyogenes and Branhamella catarrhalis. An in vitro study has shown that flavonoids from elderberry bind to the surface of the H1N1 influenza virus and interfere with host cell receptor recognition or binding. The dark violet coloured berries are a rich source of anthocyanins, and phenolic compounds such as flavonoids. A pilot trial with elderberry extract containing $175 \mathrm{mg}$ of flavonoids and anthocyanin in lozenges taken by patients with flu-like symptoms provides a beneficial effect [69-70].

\section{Marshmallow lozenges}

Benbassat et al. has developed the lozenges from marshmallow (Althaea officinalis) root aqueous extract containing polysacharides. The polysaccharides are reported for its antitussive effects and immunmodulatory effects. It reduces the local irritation and inflammation by forming a coating on the oropharyngeal mucosa. Further the root extract has been studied in albino mice and found to be nontoxic. The optimized formulation made up of sucrose and 
sorbitol base was having ideal disintegration time of 6-7 minute with better drug release [71].

\section{PhytoRelief-CC ${ }^{\circledR}$}

Phytorelief is a herbal-based sugar free lozenges developed by Alchemlife as a supplement for prevention for cold and flu. It contains herbal ingredient like Turmeric, Pomegranate and ginger as active substance having anti-inflammatory, anti-oxidant and antiedema properties. Slow dissolving of the lozenges in oral cavity leads to increase in saliva secretion which contains defence enzymes and proteins (lysine, human neutrophil defensins, histatins, Lactoferrin, Mucins, Peroxidase, $\alpha, \beta$ Defensins, Calprotectin) that acts as a barrier against bacterial and viral infection providing immunity. Further evaluation of phytorelief lozenges on human volunteers reveals that there was 50 percent reduction in cold related symptoms, complications and reduction in other treatment options in control vs treated groups [72-75].

\section{Propolis candy}

Propolis is a complex product produced by the honey bees consist of various herbal substances such as buds and natural exudates and rich in natural flavonoids. Consumption of candies containing propolis extracts has been found to increase the salivary myeloperoxidase and lactoperoxidase activity that provides antibacterial activity [76-77]. Candies containing extracts of propolis has been shown antibacterial and antifungal activity on Aggregatibacter actinomycetemcomitans and Candida albicans reported to cause oral infection [78].

\section{Micronutrients lozenges}

A triple blind randomized controlled trial done on school children with candies fortified with iron and vitamin A has been showed to be effective in reducing prevalence of anaemia in children aged 3 to 6 y [79]. Another study had done with garlic and ginger extract based herbal lozenges for antimicrobial activity against Candida albicans, Escherichia coli and Staphylococcus aureus using nystatin as positive control. The formulation inhibited growth $C$ albicans but not $S$ aureus and $E$ coli inferring that the lozenges can be used in non-resistant oral thrush.

\section{Patent review on the hard boiled candies}

Several techniques have been described in the research articles from academic filed and patent literature highlighting innumerable products, process and composition developed as hard-boiled lozenges. Application of patent is a basic tool for strengthening the mutual cooperation between academic field and corporate sectors supporting research and development of new drug delivery system. The limitation with traditional drug delivery system has triggered scientists to explore this platform tool, resulting in many patents in the area of hard-boiled candy. Some of the relevant patents are mentioned below on medicated HBL containing various active ingredients like NSAIDs, anasthetics, antacids, vitamins, nicotine, Probiotic and phytochemical actives. Some of the patented process and composition are briefly highlighted below [80].

\section{Pain relief candy}

Kirsty et al. in Rechitt Benckiser Health Care has developed hardboiled lozenges for treating in sore throat. The lozenges contains a non-steroidal anti-inflammatory drug (NSAID) flurbiprofen or ibuprofen, in molten base prepared from sugar base consist of isomalt, sucrose or liquid glucose, opacifiers, stabilizing agent, buffering agent, flavours, sweeteners, coloring agent and preservatives [81]

\section{Zinc and vitamin-C candy}

In an unique composition John C. Godfrey has developed a hard lozenges prepared from sucrose and corn-syrup that releases zinc ion and ascorbic acid in oral cavity. The purpose of this composition was to mask the aftertaste of zinc and improve the palatability [82]

\section{Nicotine candy}

Mehta et al. developed a novel delivery system of nicotine in a hardlozenges base consist of sucrose and liquid glucose. This product can be used to for smoking cessation in nicotine replacement therapy [83]
Another invention by Graham HB related to development of Nicotine candy in cigarette shaped packing containing a series of candy [84] Gian Carlo Santus developed a nicotine based sugar free lozenegs in buffered formulation in the alkaline $\mathrm{pH}$ range of 7.0 to 9.0 for better transmucosal absorption of nicotine. At alkaline $\mathrm{pH}$ nicotine will remain in unionized form resulting in better absorption [85].

\section{Antacid lozenges}

Ells Thomas and Luber Joseph have developed a hard-boiled lozenge formulation for treatment of gastric acid reflux diseases. The candy formulation consists of acid-neutralizing agent such as calcium carbonate or magnesium carbonate in a flavoured sugar base that helps in the neutralization of gastric acid [86]

\section{Tooth whitening application}

In recent times there is an increase in the awareness in the oral hygiene. Tooth whitening products are getting significant demand among consumers. The products are segmented as whitening gels, strips, mouthwash and toothpaste that helps in brightening of teeth by removing surface stains through bleaching action. Currently available OTC tooth whitening products contain bleaching agents such as hydrogen peroxide, and carbamide peroxide. Henryk Jakubowski has developed an innovative sugar free candy composition that contains citric acid, calcium peroxide, sodium bicarbonate. It releases hydrogen peroxide when calcium peroxide reacts with citric acid in saliva. It makes the teeth white by removing tartar, plaque, calculus, and stains $[87,88]$

\section{Candies for dental caries}

The invention deals with preparation and composition of hard candies for remineralisation of dental caries and dental plaques. The candies contain a therapeutically required amount of calcium and phosphate salt such as calcium glycerophosphate, calcium lactate, calcium gluconate, $\alpha$-tricalcium phosphate, calcium glycerophosphate, sodium dihydrogen phosphate dihydrate in sugar free or sugar-based candy. The candies acts through deposition of calcium and phosphate ions into oral cavity and on dental plaque resulting in remineralisation and repair of the cariogenic teeth [89]

\section{Anaesthetic property}

The anaesthetic candy contains active ingredient lidocain and benzocaine in a hard candy base prepared from either of sugar or sugar free base. The invention is for purpose of oral pain relief from sore throat, cough and canker sores [90] In addition to above described patented products there are numerous patents have been described. Below is the list (table 2) of few patents on functional and medicated innovations on hard boiled lozenges.

\section{Formulation}

The hard boiled lozenges are having a weight ranging from 2.5 to 3.5 gram with the active pharmaceutical ingredients. Hard boiled lozenegs are formulated using various components such as lozenegs base like sucrose, liquid glucose, isomalt, sorbitol; binder such as gum acacia, methyl cellulose; FDandC colors; flavouring agents; humectants like glycerin, propylene glycol and organic acids [11]. The general composition of the hard boiled candies is shown in table 3.

\section{Bulking agent and sweeteners}

Bulking agent and sweeteners are the major component of hard-boiled lozenges. They are generally consists of liquid glucose, sucrose, fructose, dextrose, sugar free low-caloric substances like isomalt, erythritol, sorbitol, lactitol and maltitol. The liquid glucose made from acid, enzyme and acid-enzyme combination hydrolysis of corn starch. It is available in various grades depending on the dextrose equivalent (DE) such as 42-DE and 60-DE. The major role of liquid glucose in hard lozeneges is to control crystallization, add body, to adjust the sweetness level. As the sugar based candies poses the risk of dental caries, sugar free lozenges made of maltitol syrup, isomalt, aspartame, plant based sweeteners such as monk-fruit sweeteners and stevioside are being recently explored as a substitute for sweeteners. The sweetness index of erythritol, Isomalt, Sorbitol, xylitol, aspartame and stevioside are $0.7,0.4,0.5,0.95,200$ and 300 as compared to sucrose with relative sweetness of one [91]. 
Table 2: Patented technology on hard-boiled lozenges

\begin{tabular}{|c|c|c|c|c|}
\hline S. No. & Title & Patent number & Active ingredients & Therapeutic indication \\
\hline 1 & $\begin{array}{l}\text { An anti-motion sickness throat } \\
\text { lozenge }\end{array}$ & $\begin{array}{l}\text { CN } 105412876 \text { A } \\
20160323\end{array}$ & Ginger extract & Anti-motion sickness \\
\hline 2 & $\begin{array}{l}\text { A throat lozenge for treating acute } \\
\text { pharyngitis, and its preparation } \\
\text { method and application thereof }\end{array}$ & $\begin{array}{l}\text { CN } 104840566 \text { A } \\
20150819\end{array}$ & $\begin{array}{l}\text { Nepalese polygonum, Auricled, Hedyotis, } \\
\text { Bulleyanachang, }\end{array}$ & Acute pharyngitis \\
\hline 3 & $\begin{array}{l}\text { Herb extract-containing lozenge } \\
\text { composition for treating inflammatory } \\
\text { diseases of the mouth and pharynx }\end{array}$ & $\begin{array}{l}\text { WO } 2010003472 \text { A2 } \\
20100114\end{array}$ & Herbal extracts & $\begin{array}{l}\text { Inflammation in mouth and } \\
\text { pharynx, cough, and upper } \\
\text { respiratory tract infection }\end{array}$ \\
\hline 4 & $\begin{array}{l}\text { Herbal formulations comprising } \\
\text { cineole, eugenol, and vasicine as } \\
\text { cough lozenge }\end{array}$ & $\begin{array}{l}\text { WO } 2006067600 \text { A2 } \\
20060629\end{array}$ & Clove, Adhatoda vasaka, Eucalyptus oil & Coughs and sore throat. \\
\hline 5 & $\begin{array}{l}\text { Process for addition and } \\
\text { stabilization of vitamin-C in a hard } \\
\text { candy-like comestible }\end{array}$ & USP 4692339 & Sodium ascorbate and ascorbic acid & $\begin{array}{l}\text { Antimicrobial and } \\
\text { nutritional supplement }\end{array}$ \\
\hline 6 & $\begin{array}{l}\text { Herbal cough candy and process for } \\
\text { the preparation of the same }\end{array}$ & $\begin{array}{l}\text { Indian Pat. Appl. } \\
\text { (2014),IN- } \\
\text { 2012DE03038 A } \\
20140425\end{array}$ & $\begin{array}{l}\text { Vitis vinifera, Terminalia chebula, Piper } \\
\text { longum, Glycyrrhiza glabra, Cinnamomum } \\
\text { zeylanicum, Melaleuca leucodendron, } \\
\text { Eucalyptus oil, sugar and liquid glucose } \\
\text { base }\end{array}$ & $\begin{array}{l}\text { Minor throat infections and } \\
\text { laryngitis }\end{array}$ \\
\hline 7 & $\begin{array}{l}\text { Synergistic herbal blood detoxifier } \\
\text { formulation }\end{array}$ & $\begin{array}{l}\text { Indian Pat. Appl. } \\
\text { (2012), IN } \\
\text { 2010DE02545 A } \\
20120427\end{array}$ & $\begin{array}{l}\text { Echinacea purpurea leaves, Andrographis } \\
\text { paniculata } \\
\text { leaves, Boerhaavia diffusa whole plant, } \\
\text { Arctiumlappa root, Rubia cordifolia root, } \\
\text { Pothosaureus, leaves of Ixora coccinea, } \\
\text { stems of Jacaranda mimosa folia, roots of } \\
\text { Hemidesmus indicus, the heartwood of } \\
\text { Acacia catechu, stem of Cassia biflorain, } \\
\text { leaf of Cassia seamia and flower of Dahlia } \\
\text { pinnata. }\end{array}$ & Blood purification \\
\hline 8 & $\begin{array}{l}\text { Therapeutic herbal lozenge } \\
\text { composition }\end{array}$ & $\begin{array}{l}\text { U. S. Pat. Appl. Publ. } \\
\text { (2006), US } \\
20060251731 \text { A1 } \\
20061109\end{array}$ & $\begin{array}{l}\text { Osha root, lobelia herb. licorice root, } \\
\text { yerba santa leaf, eyebright herb, cats } \\
\text { claw, rosemary, ginger, green tea leaf, } \\
\text { grape seed, and peppermint }\end{array}$ & Enhances respiration \\
\hline 9 & $\begin{array}{l}\text { Development of anti-cough, anti- } \\
\text { tussive and throat soothing herbal } \\
\text { formulation }\end{array}$ & $\begin{array}{l}\text { U. S. Pat. Appl. Publ. } \\
\text { (2004), US } \\
20040126441 \text { A1 } \\
20040701\end{array}$ & $\begin{array}{l}\text { Extract of Piper cubeba, } \\
\text { Glycyrrhiza glabra, Acorus calamus, } \\
\text { Alpinia galanga, Zingiber officinale }\end{array}$ & Anti-cough, anti-tussive \\
\hline 10 & $\begin{array}{l}\text { Herbal formulation of Gymnema } \\
\text { sylvestre as a dietary aid }\end{array}$ & $\begin{array}{l}\text { U. S. Pat. Appl. Publ. } \\
\text { (2004), US } \\
20040071801 \text { A1 } \\
20040415\end{array}$ & Gymnemic acid & $\begin{array}{l}\text { Dietary aid for controlling } \\
\text { sweet intake }\end{array}$ \\
\hline 11 & Candy for larynx & CN 200510024625 & $\begin{array}{l}\text { licorice, dried tangerine peel, boat- } \\
\text { fruited sterculia seed }\end{array}$ & Cough relief \\
\hline 12 & $\begin{array}{l}\text { Process for making a hard-candy- } \\
\text { based oral pharmaceutical lozenge } \\
\text { containing an antacid. }\end{array}$ & $\begin{array}{l}\text { US5616340 (1997) } \\
\text { US5399354 (1995) }\end{array}$ & $\begin{array}{l}\text { calcium carbonate or magnesium } \\
\text { carbonate }\end{array}$ & Antacid \\
\hline 13 & $\begin{array}{l}\text { Production process for NSAID- } \\
\text { containing lozenges, their } \\
\text { compositions, their medicinal use }\end{array}$ & US10328039 (2019) & NSAIDs & Sore throat \\
\hline 14 & $\begin{array}{l}\text { Medical cannabis lozenges and } \\
\text { compositions there of }\end{array}$ & US9504723 (2016) & Cannabidiol and tetrahydrocannabinol & Psychoactive drug \\
\hline 15 & $\begin{array}{l}\text { Suckable-flurbiprofen lozenges for } \\
\text { treatment of sore throat }\end{array}$ & US $6166083(2020)$ & Flurbiprofen & Sore throat \\
\hline
\end{tabular}

Table 3: Basic composition of a typical sugar and sugar free hard-boiled lozenges [92, 93]

\begin{tabular}{lll}
\hline Sugar-based hard-boiled lozenges & Concentration (\%w/w) \\
\hline S. No & Components & $58-60$ \\
1 & Sucrose & $38-40$ \\
2 & Liquid glucose & $1-3$ \\
4 & Active Ingredients & 0.5 \\
5 & fruit acids & q.s. \\
6 & Flavours and Colours & Concentration (\%w/w) \\
Sugar-free hard-boiled lozenges & $97-100$ \\
S. No & Components & $1-3$ \\
1 & Isomalt & \\
2 & Active Ingredients & \\
3 & Fruit acids & \\
4 & Artificial sweeteners & q.s. \\
5 & Flavours and Colours & q.s \\
\hline
\end{tabular}




\section{Active pharmaceutical ingredients}

Various active pharmaceutical ingredients can be incorporated into the hard lozenges. The commonly used active ingredients are having properties such as local anaesthetics, antiseptics, antimicrobial, antiviral, analgesics, and demulcent properties. Peppermint oil, l-menthol, eucalyptus oil, benzocain, amylmetacresol, hexylresorcinol, cholohexidine hydrochloride, diphenhydramine hydrochloride, cetylpyridinium chloride are used in many over the counter (OTC) lozenges used for sore throat and cough. Some of the lozengescontain pain killers such as flurbiprofen. One of the lozenges called Actiq ${ }^{\mathrm{TM}}$ contains an opioid analgesic fentanyl. Zinc gluconate lozenges and zinc acetate lozenges are common zinc based lozenges used in various common cold symptoms. Many of the lozenges contain various herbal extracts such as extract of liquorice, Echinacea sp. Elderberry extract having anti-viral and anti-microbial properties $[47,48,99]$.

\section{Hydrophilic polymers}

Addition of hydrophilic polymers prolongs oral retention time of hard boiled candies by delaying the disintegration time of lozeneges. The most commonly used polymers are gum-acacia, hydroxyl propylmethyl cellulose, xanthan gum, guar-gum, and carboxy methyl cellulose $[39,92]$.

\section{Flavours}

Flavours are needed to improve the palatability by masking bitter and nauseating taste of the incorporated drug. Further the flavour plays to attract the consumers and to distinguish the products. Amount flavour needed depends upon its nature and strength. Generally flavours are either used in single or as fusion flavours with combination of two or more flavours. The common flavours used are peppermint menthol, eucalyptus oil, ginger, and various fruit flavours. Menthol is a cooling flavour that provides a cooling effect by binding to cooling receptor called TRPM8. Schober AL and Peterson DG has studied with combination two flavours 1-8 cineole and menthol in hard lozenges by breath analysis and sensory timeintensity, and found that the intensity of the flavour is affected by interaction of flavoured compounds. It has been observed that, single flavour lozenges have a better release rate as compared to the mixture. For evaluation of flavour and to discriminate various types of the flavours electronic tongue is used $[91,100]$

\section{Humectants}

Humectants such as invert sugar, glycerine are used in the lozenges to prevent from drying brittleness and to enhance the cold flow properties. Most commonly used humectants are glycerine and propylene glycol in 0.5 to $2 \% \mathrm{~s}$ [101].

\section{Organic acids and buffers}

Various acidulents and buffers such as potassium carbonate, potassium bicarbonate, sodium carbonate, sodium bicarbonate, potassium citrate, sodium citrate, and their combinations, various organic acids like citric acid, tartaric, malic acid, ascorbic acid, lactic acid, gluconic acid are used in hard candies to stimulate saliva secretion in buccal cavity which facilitate the dissolution of lozenges in the buccal cavity. Further, these ingredients provide ideal $\mathrm{pH}$ in buccal cavity to facilitate absorption of active ingredients through buccal mucosa. Further uses of acidulents also provide a persistent taste and strengthen the flavour and compensate the aftertaste highintensity sweeteners in sugar-free lozenges $[15,97,102]$.

\section{Colouring agents}

Colouring agents under FD and $\mathrm{C}$ and customized food-grade colours are used for the desired shades of the colour.

\section{Manufacturing procedure}

The hard-boiled lozenges are solid amorphous products with a glassy appearance prepared by heating, melting and quick congealing method into the desired moulded shape. They are either made of sugar such as sucrose and liquid glucose or may be sugarfree prepared from isomalt. A general manufacturing process of both sugar-based and sugar-free hard lozenges is mentioned below.

\section{Sugar-based hard lozenges}

The basic components of hard lozenges are sugars such as sucrose, fructose, glucose and liquid glucose or maltose syrups, colours, flavours and acids. Commonly the hard-boiled lozenges are made up of a mixture of sucrose and liquid glucose in proportion ranging from 40:60 to $65: 35$ by weight. The general process of making hard lozenges involves mixing of sugar and liquid glucose with excess of water and dissolving sugar under heat to make homogenous syrup mass. It is concentrated at temperature of $130-150{ }^{\circ} \mathrm{C}$ under vacuum and stem pressure to reduce the moisture content below 1-2\% [68]. Then molten mass is cooled to temperatures of 90 to $115^{\circ} \mathrm{C}$, during this time other components such as colours, flavours, acids, stabilizers and active ingredients are added and homogenously mixed and subsequently put into mould of proper shape and passed through the cooling tunnel at temperature of $25-30{ }^{\circ} \mathrm{C}$ under relative humidity of $40-50 \%$. The temperature at which the molten lozenge matrix gets transformed to amorphous glassy state from liquid is knownas glass transition temperature $\left(\mathrm{T}_{\mathrm{g}}\right)$. Colours and flavours are incorporated homogenously in the hard lozeneges in its glassy stage. $\mathrm{T}_{\mathrm{g}}$ value decreases with increase in water content and with increase in the molecular weight of sugars used in the candy. $\mathrm{T}_{\mathrm{g}}$ value of some of the common confectionary sweeteners such as fructose, glucose, lactose, maltose, sucrose, sorbitol, xylitol, and maltitol are 5-10,31, $101,87,62-70,-9,-29,39,63.6$ and that of 42 DE and 20 DE liquid glucose are 79 and $139^{\circ} \mathrm{C}$, where DE stands for dextrose equivalent. But in the hard lozenges prepared from mixture of sweeteners value of $T_{g}$ depends of the ratio of the different sweeteners mixed and have $\mathrm{T}_{\mathrm{g}}$ value in between the sugar components used in the mixture. Differential scanning calorimetry (DSC) is the most common method to measure the glass transition temperature [76].

\section{Sugar free hard lozeneges}

Commonly sugar-free hard-boiled lozeneges are made up of maltitol syrups, sorbitol syrup and powdered maltitol, mannitol, erythritol and isomalt. Isomalt is among the most predominantly used base for the manufacture of sugar-free lozeneges. The basic composition of lozeneges consists of isomalt with the flavours, colours, acids and intense sweeteners such as sucralose and acesulfame $\mathrm{K}$. The isomalt and water in ratio of 75:25 is boiled under vacuum to evaporate the water content to $2.5 \%$ of less cooled and moulded to room temperature with the addition of various substances such as sweeteners, acids, flavourings, colourings, acids, herbal extracts and pharmaceutical active ingredients. Because of the low solubility of isomalt, higher temperature of $150-200{ }^{\circ} \mathrm{C}$ and more time and high quantity of water is needed for the dissolution of isomalt $[60,63]$. Other process is similar to above manufacturing procedure of sugar based hard lozenges. The isomalt lozenges have advantages as compared to the sugar-based lozeneges due to their low water solubility leading to extended action and slow releases of the actives $[94,103]$

\section{Critical control parameters}

The quality of lozenges such as hardness, texture and stability depends on various parameters such as quality of water, $\mathrm{pH}$ of water used in the formulation, cooking temperature during the preparation of candy. Below are mentioned some of the critical parameters of the hard-boiled lozenges.

\section{Residual moisture content}

In the manufacturing procedure of hard-boiled lozenges water is used for dissolving the sugar and other components used in formulation. All the materials should be completely dissolved in order to prevent the crystallization of the sugars in the finished product as well during further processing. The water should be reduced in the final formulation to 1-2 percentages. The percentage of water in the hard-boiled lozenges affects texture, shelf life and microbial stability. Higher moisture content leads to soft texture, graining or stickiness, loss of flavour, growth of microbes such as yeasts, molds and bacteria for hard lozenges. Further higher moisture content leads lower glass transition temperature, which affects the shelf life of hard lozeneges [103]. 


\section{pH of water}

$\mathrm{pH}$ of water is one of the critical attributes that affects the texture and appearance of the hard lozenges. For ideal glassy appearance the $\mathrm{pH}$ of water should be neutral. Acidic water with $\mathrm{pH}$ below 6.0 along and high processing temperature during manufacturing process results in increase of reducing sugar due to inversion causing discoloured and sticky texture to lozeneges [97-98].

\section{Storage temperature of hard boiled lozeneges}

For desired shelf life the hard lozeneges should be storage temperature should be below their glass transition temperature. As the hard lozenges are thermodynamically unstable amorphous products, storage condition above the glass transition leads to crystallisation of sucrose in hard lozenges leading to lose its glassy appearance and texture. Ideally high humidity and temperature should be avoided for storage of hard boiled lozeneges $[97,98]$.

\section{Evaluation of hard boiled lozenges}

Characterization and evaluation of the hard boiled lozenges is done by following tastes and methods.

\section{Organoleptic evaluation}

Human taste panels are used for evaluation of physical appearance such as uniformity of colour, odour, shape, size and sweetness. In vitro taste evaluation is performed by using electronic tongue equipped with taste sensors or. One of the electronic taste sensing system is SA402B equipped with sensors imitating the taste stimuli and sensory signals that provides an understanding of taste qualities. This is also used for taste evaluation of other products such as food, beverages, and pharmaceuticals [105].

\section{Physicochemical quality control parameters of the lozenges}

It includes quality control parameters such as $\mathrm{pH}$, size, weight variation, hardness or crushing strength of lozenges, Friability test, content uniformity and time for dissolving of the lozenges.

\section{pH value}

he $\mathrm{pH}$ value of the lozenge is determined by dissolving one lozenge in $100 \mathrm{ml}$ of distilled water and measuring by $\mathrm{pH}$ meter electrode. Determination of $\mathrm{pH}$ is one of the important parameter as extreme acidic and basic $\mathrm{pH}$ leads to irritation of buccal mucosa as well the $\mathrm{pH}$ also affect the taste of lozenges.

\section{Size}

The dimensional parameters such as thickness and length are measured by micrometer or digital slide caliper. The parameters are controlled within a parameter of $\pm 5 \%$ variation from standards and expressed in millimetre.

\section{Weight variation}

As per the method described in USP weight variation testis done by weighing 20 lozenges individually on an electronic balance, calculating the average weights and comparing with individual weights. The measure of weight variation is expressed as percentage using the below formula. According to USP not more than 2 of the individual weights of lozenegs should deviate from average weight by more than $5 \%[106,107]$.

\section{Hardness test/Crushing strength}

The hardness of the lozenges measures the force required to break the lozenges diametrically into halves by compression with a coiled spring and is expressed in $\mathrm{kg} / \mathrm{cm}^{2}$. The hardness is measured by using hardness tester like Pfizer or Monsanto and electromechanical equipment EHT5PR. Some of the factors that affect the hardness are geometry, dimension, orientation and composition of formulation [106].

\section{Friability test}

Friability test is performed to access the effect of friction, shocks, vibration, on capping or breaking of lozeneges. Roche-friabilator is used for this test. According to USP-NF the lozenges complies with the test if friability loss is less than $1 \%$ of their weight [106].

\section{Uniformity of content}

To ensure the efficacy of the lozenges the quantity of the active drug needs to be monitored from lozenges to lozenges and from batch to batch. Content uniformity is determined by using suitable analytical methods such as HPLC, HPTLC or GC. According to USP the formulation complies with the test if individual content is between 85 percent to 115 percent average content $[106,108]$.

\section{Ash value}

Ash value indicates presence of the inorganic substance in the product. As per FSSAI standards of India sulphated ash of lozeneges should be not more than $2.5 \%$ and acid insoluble ash should not be more than 0.2 percent.

\section{Mouth dissolving time}

USP-disintegration apparatus is used for this test. To determine the dissolution time one of lozenges is placed in the tube of basket rack. Then the basket rack is immersed in $900 \mathrm{ml}$ vessel containing buffer solution at $\mathrm{pH}$ of 6.8 maintained temperatures of $37^{\circ} \mathrm{C}$ equivalents to buccal cavity condition. The basket assembly is subjected to up and down motion with a motor driven device through a distance of $5-6 \mathrm{~cm}$ at frequency of 28 to 32 cycles per minute. Perforated plastic discs are used to prevent the floating of lozenges. The apparatus is operated for $30 \mathrm{~min}$. To comply the test, lozenges must dissolve completely without any particles on 10-mesh screen within 30 minute. Normally the dissolution time depends on the composition of the hard boiled lozenges and it varies from 6 to $10 \mathrm{~min}$. Further human panel can be used to determine the actual dissolution time of the hard boiled lozenges $[11,109]$.

\section{Dissolution}

Dissolution experiment is performed to study the drug-release profile and solubility of the final formulation. Generally the dissolution is done in USP apparatus II in simulated saliva fluid at temperature between $33-37{ }^{\circ} \mathrm{C}$ and $\mathrm{pH}$ of 6.8 related to the buccal conditions. The composition of some dissolution medium suitable for lozenges is given below [11].

\section{Composition-I}

Mashru et al. has reported the dissolution medium for a salbutamol sulphate oral fast dissolving film. The composition for simulated salivary fluid consist of components sodium chloride (8 gm) ptassiumdihydrgen phosphate $(0.190$ g) Sodium hydrogen phosphate dihydrate $(2.984 \mathrm{~g})$, demineralized water $(1000 \mathrm{ml})$ and adjusted to $\mathrm{pH}$ of 6.80 with Phosphoric acid [11].

\section{Composition-II}

According to German Drug Codex (DAC) and New German Formulary (NRF) the artificial saliva consist of sodium chloride (0.085 g), potassium chloride $(0.120 \mathrm{~g})$, Sodium monohydrogen phosphate dodecahydrate $(0.250)$, Sorbic acid $(0.1 \mathrm{~g})$, Calcium chloride $(0.15 \%)$ or Magnesium chloride $(0.05 \%)$ (10 g), carmellose sodium (0.5 g), $70 \%$ sorbitol solution (4. g), demineralized water (84.645 g) [11].

\section{Composition-III}

Yingyi $\mathrm{M}$ et al. have described the preparation method of artificial saliva with $3 \%$ mucin with $\mathrm{pH} 6.8$ to simulate buccal condition. It consist of sodium chloride- $\mathrm{NaCl}$ (1.594 g), ammonium nitrateNH4NO3 (0.28 g) Potassium di hydrogen phosphate-KH2PO4 $(0.66$ g), potassium chloride-KCl (0.202 g), potassium citrate-K3C6H507. H2O- $(0.08 \mathrm{~g})$, sodium salt of uric acid (C5HN40. $\mathrm{Na}(0.021 \mathrm{~g})$, ureaH2NCONH2 $(0.198 \mathrm{~g})$, sodium salt of lactic acid-C3H5ONa (0.146 g), porcine gastric mucin-Type-II (30 g),in $1000 \mathrm{ml}$ of water [91]. Dissolution studies for some of the lozenges as per FDA monographs and other research reports are described below.

\section{Zinc and vitamin-C lozeneges}

It is used for systemic action. In vitro dissolution study of this lozenge is performed in USP dissolution test apparatus-II (Paddle type) at $75 \mathrm{rpm}$ in $900 \mathrm{ml}$ of $0.1 \mathrm{~N}$ hydrochloric acid. The sample is withdrawn after 60 minute for testing [11]. 


\section{Nystatin lozeneges}

Nystatin is an antimycoticpolyene antibiotic used for treatment of oral candidiasis. In vitro dissolution study of this lozenge is performed in USP disintegration apparatus at 29-32 rpm in demeralized water. The sample is withdrawn after 90 minute for testing [11].

\section{Fentanyl citrate lozeneges}

Fentanyl citrate is a pain killer used for systemic action. In vitro dissolution study of the lozenge is performed in USP dissolution apparatus II (paddle type) at $175 \mathrm{rpm}$. Dissolution medium used was $0.1 \mathrm{M}$ phosphate buffer with $\mathrm{pH} 6.8$ and the sample was withdrawn in interval of 5, 10, 20, 30 and 40 min for analysis [11].

\section{Nicotine polarcrilex lozeneges}

It is used for systemic action in order to stop smoking. In vitro dissolution study is carried out USP dissolution apparatus (basket type) at $100 \mathrm{rpm}$. Phosphate buffer with $\mathrm{pH} 7.4$ is used as dissolution medium for study of drug release and the sample is withdrawn at time interval of $0.5,1,2,3,6$ and 8 hour [11].

\section{Itraconazole lozeneges}

Deepika M et al. have reported dissolution study for Itraconazole lozenges formulated for oropharyngeal candidiasis. They have used USP dissolution test apparatus type II (paddle type) at $100 \mathrm{rpm}$. Phosphate buffer with $\mathrm{pH} 6.8$ at $37 \pm 0.5^{\circ}$ Ccontaining $2 \%$ SLS was used as dissolution medium for in vitro drug release studies. The sample was analysed by using UV-visible spectrophotometer at 262 $\mathrm{nm}$ to calculate the drug release [6].

\section{Clotrimazole lozeneges}

Nagoba SN et al. have performed the dissolution study of the clotrimazole lozenges made from sugar and liquid base. $100 \mathrm{ml}$ of phosphate buffer ( $\mathrm{pH}$ 6.5) in a beaker stirred at $100 \mathrm{rpm}$ was used as dissolution medium. $5 \mathrm{ml}$ of samples were withdrawn at time of interval of 5 minute and analyzed by UV-visible spectrophotometer at $272 \mathrm{~nm}$ [35].

\section{Albendazole lozenges}

Neha D et al. have carried out the dissolution of the hard boiled lozenges formulated from sucrose, dextrose and sorbitol solution. In vitro dissolution study of the lozenge is performedin USP dissolution apparatus II (paddle type) at $100 \mathrm{rpm}$. Phosphate buffer with $\mathrm{pH} 4.5$ at $37 \pm 5{ }^{\circ} \mathrm{C}$ is used as a dissolution medium and the sample is withdrawn in time interval of $5 \mathrm{~min}$ for $30 \mathrm{~min}$. Drug release from the lozeneges was analyzed by UV-visible spectrophotometric methods at $295 \mathrm{~nm}$ [39].

\section{Evaluation of buccal permeation}

As the lozenges formulation intended to be slowly dissolve in the mouth for release of drug in buccal cavity. Buccal delivery is having the advantage of bypassing the gastrointestinal and stomach drug degradation and reducing first pass effects. Evaluation of mucosal permeability is one of the vital parameter for pharmacokinetic study of the drug before the market approval. On the basis of physiological structure of human buccal transmucosal membrane various methods are reported in the literature for in vitro evaluation of buccal mucosal absorption study.

The commonly used methods are animal buccal mucosa, animal non-buccal mucosal models, cell models, biomimetic barrier model, and AMI-system and diffusion cells. The classification of various permeation models used for permeation study is mentioned in table 4 this method provides insights about extent of drug delivery, rate of drug absorption, permeation, and bioavailability across the buccal mucosa $[110,111]$.

Table 4: List of in vitro permeation model

\begin{tabular}{|c|c|c|c|}
\hline S. No. & $\begin{array}{l}\text { Permeation } \\
\text { model }\end{array}$ & Description and characteristics & References \\
\hline \multirow[t]{2}{*}{1} & Animal buccal & 1. Porcine and bovine buccal mucosa & \\
\hline & mucosa & $\begin{array}{l}\text { 2. Nonkeratinized and similar physiological structure, thickness, morphology and composition to } \\
\text { human buccal mucosa }\end{array}$ & {$[110,111]$} \\
\hline \multirow[t]{3}{*}{2} & Animal non- & 1. Porcine esophageal mucosa: histology and lipid composition is similar to human buccal mucosa & \\
\hline & buccal mucosa & $\begin{array}{l}\text { 2. Chick chorioallantoic membrane: The composition is similar to human buccal mucosa except } \\
\text { absence of mucous layer }\end{array}$ & {$[110,111]$} \\
\hline & & 3. Used as substitute when porcine buccal mucosa is not available & \\
\hline \multirow[t]{2}{*}{3} & Cell model & 1. Hamster cheek pouch cell, TR146, EpiOralR ${ }^{\mathrm{TM}}$ & \\
\hline & & $\begin{array}{l}\text { 2. Have morphological and physiological function similar to human buccal mucosal epithelial cells } \\
\text { 3. Used for investigate drug permeation, toxicity, transport mechanism through oral mucosa }\end{array}$ & [111] \\
\hline \multirow[t]{2}{*}{4} & Biomimetic & 1. It is an artificial non-tissue and non-cellular model consist of artificial membrane and lipids. & \\
\hline & barrier model & $\begin{array}{l}\text { 2. Some of the models are Parallel Artificial Membrane Permeation Assay (PAMPA), Phospholipid } \\
\text { Vesicle-based Permeation Assay } \\
\text { (PVPA), Permeapad® and Artificial Membrane Insert System (AMI-system). } \\
\text { 3. Used for study of passive transport of the drug }\end{array}$ & [111] \\
\hline 5 & Diffusion cells & $\begin{array}{l}\text { 1. Various types includes vertical diffusion cells (Franz diffusion cell, Flow-through diffusion cell) } \\
\text { and side-by-side horizontal diffusion cells (Ussing diffusion cell, Sweetana-Grass diffusion cell). } \\
\text { 2. Used for study of rate of permeation of drugs }\end{array}$ & [111] \\
\hline
\end{tabular}

\section{Methods of characterization}

\section{Thermoanalytical methods}

Differential scanning calorimeter (DSC) is the used to study the thermodynamic properties drugs, drug and excipients compatibility, and crystal nature of the drug. Appearance of the endothermic peak of the drug and excipient at its melting point indicates the compatibility of drug with formulation. The change in melting point of the active ingredients confirms potential interaction between drug and excipients. The commonly used instruments used to study the thermodynamic properties are DSC (PerkinElmer Inc.), DSC2010 (TA instruments) and Shimadzu DSC-60 plus. The analysis is performed by taking 4-6 $\mathrm{mg}$, of indium pan and heating with temperature gradient depending on melting temperature under nitrogen or argon flow [96-112].

\section{Powder X-ray difractometry (PXRD)}

Powder X-ray diffraction (PXRD) is used for study of crystalline or amorphous nature of drug molecules. XRD confirms possible change in the polymorphism of the drugs after processing. The presence of the intense sharp peaks indicates crystal nature of the drug while reduced intensity of the peaks indicates amorphous nature of drug after dispersion. The commonly used instrument for XRD study are D8 Advance X-ray diffractometer (Bruker, Germany) and X'pert Pro Analytical (Netherland) [92-117]. 


\section{Fourier transform infrared spectroscopy (FTIR)}

Fourier transform infrared spectroscopy (FTIR) is performed to study the drug-excipient interaction studies. The FTIR fingerprint of pure drug is compared with its finished formulation. Similarity of characteristic peaks of drug with its formulation indicates any physical and chemical interaction between drug and excipients. The instrument used are PerkinElmer in KBr pellets methods or by Nicolet ${ }^{\mathrm{TM}}$ iS50 FTIR (thermo scientific) or Bruker alpha II FTIR in ATR mode with diamond crystal using direct sample for analysis [119].

\section{Solid-state nuclear magnetic resonance (NMR) 23+}

Solid-state NMR technique is used for study drug properties drug at atomic level and to study crystalinity nature of the materials. Solidstate NMR provides information about chemical stability of drug and excipients that helps in study of degradation processes of drugs in the solid state. SS-NMR is also used to determine the residual water molecules that are present in the interior of crystal lattice of the formulation [119].

\section{Microscopy}

Microscopy method is used to study crystals or amorphous nature of materials, surface morphology, size, shape and distribution of drug in the formulation. Scanning electron microscopy (SEM) is used for study of distribution pattern of the drug within the lozenges and to analyse microstructure of the lozeneges. The common instruments used for it are FEI-Quanta 450 and EVO-18 Zeiss microscope [115].

\section{Moisture analysis}

Moisture content is a critical parameter for quality of the lozenges and affects its stability and shelf life. At lower moisture content sucrose within lozenges remain in an amorphous or glassy state. Storage temperature above its glass transition temperature causes crystallisation of sucrose affecting the texture and glassy appearance leading end of shelf life. Excess moisture also affects microbial stability, enzymatic and non-enzymatic reactions during storage. For better shelf life the moisture content of a hard candy should be in the ranges of 2-5\%. Various methods used for moisture analysis are loss on drying method, Nuclear Magnetic Resonance (NMR) and Nearinfra red technique (NIR), and karl-fischer titration. In NIR Water gives signals at 1450 and $1940 \mathrm{~nm}$, based on different vibrational modes, which are used to quantify the water content [96].

\section{Taste evaluation}

Taste is one of the most important organoleptic properties that influence patient acceptance and compliance. Therefore taste evaluation is one of the important parameter of quality control. Taste evaluation is done both by electronic taste sensing system and human taste penalists. But for the drug with narrow therapeutic index the human penalists is not suitable so electronic tongue is preferred. The electric tongue is equipped with a taste sensing system having sensors for various taste signals such as umami, saltiness, astringency, bitterness and sourness $[120,121]$. The Insent taste sensing system SA402B was used equipped with 7 sensors of various taste stimuli has been found to be one of promising tool for taste evaluation of complex products $[122,123]$.

\section{Stability studies of hard boiled lozenges}

The shelf life of the herbal drug based hard lozenges is determined by conducting the stability studies as per the ICH guidelines. It helps to determine the length of time that substance maintains its acceptable level of quality without undesirable physicochemical qualities and safe microbial limits. The stability parameter includes total bacterial count, total yeast and mold, pathogens such as Escherichia coli, salmonella species, Staphylococcus aureus, Pseudomonas species, and physical parameters like texture, color, odour, taste, hardness, stickiness, moisture content, crystallization, and assay of the active ingredient [124-125].

\section{Packaging of hard boiled lozenges}

Packing conditions are critical for storage, protection and stability of the dosage form. As the hard boiled lozenges are extremely moisture sensitive it needs immediate packing after cooling and moulding for protection from light and moisture. Some of the common packing material used for hard boiled lozenges multilayer laminate in different combination like polyester (PET), low density poly ethylene (LDPE), metallized polyester (MET PET), and polypropylene (PP) aluminium foils, pouch, and blister packs made from opaque PVC with aluminium foil. Among the above packing materials aluminium foil has been found to most effective in protection for the active drug. For secondary packing HDPE and PET bottles are also used as suitable material. While packing the environmental conditions in the packaging area should be maintained at optimum humidity and temperature to prevent sticking by moisture. For example isomalt lozenges need 40 to $50 \% \mathrm{RH}$ at 20 to $25{ }^{\circ} \mathrm{C}$. The printing ink should be non-toxic and utmost care should be taken to prevent contact of ink with the product [10].

\section{Regulatory aspects of hard boiled lozenges}

All the ingredients used for lozeneges formulation should be of pharmacopoeia quality. For example Isomalt is approved under FDA as an inactive ingredient. Isomalt is available in pharmaceutical grades according to the monograph on in the European Pharmacopoeia and USP-NF. Further the product should comply with the various required parameters such as heavy metal limits for Arsenic(As), Lead (Pb), Cadmium(Cd), Mercury(Hg), and microbial contaminant such as total microbial plate counts, total yeast and molds, pathogen count such as Escherichia coli, Enterobacteriaceae, Coliforms, Pseudomonas aeruginosa, Staphylococcus auerus, Salmonella sp., aflatoxin, as per the pharmacopoeial standards. For examples as per the Ayurvedic Pharmacopoeia of India the heavy metal content for Arsenic (As), Lead $(\mathrm{Pb})$, Cadmium (Cd) Mercury (Hg) should be $3 \mathrm{ppm}, 10 \mathrm{ppm}, 0.3 \mathrm{ppm}$ and $1 \mathrm{ppm}$ respectively, total microbial plate count $\left(10^{5} \mathrm{cfu} / \mathrm{g}\right)$, total yeast and mold $\left(10^{3} \mathrm{cfu} / \mathrm{g}\right)$, aflatoxin-B1, B2, G1 and G2 limit is $(0.5$ ppm, $0.1 \mathrm{ppm}, 0.5 \mathrm{ppm}$, and $0.1 \mathrm{ppm}$ respectively) [126]. List of ingredient composition of the product should be mentioned on the product label. The lozenges having therapeutic claim should be supported by relevant clinical trials such as lozenges with therapeutic claims like, sore throats, beneficial for the respiratory system should be substantiated by relevant clinical trials [127].

\section{CONCLUSION}

The hard-boiled lozenges are having immense potential as an attractive, differentiated and efficient drug delivery dosage form. Various clinical trials have confirmed better bioavailability and improved absorption of drugs for both local and systemic effects. The present manuscript highlights various innovative patented application as well academic publications on hard-boiled lozenges. Application of hard-boiled lozenges for throat infection, cough relief, anti-infective, antifungal, Immunity boosting, smoking cessation, antacid, oral care, dental care and tooth whitening are some of the exciting application. The article further provides information of various commercial products available in the market in form of hard-boiled lozenges. So the HBL can be an alternative platform technology for manufacturing of pharmaceutical dosage for drug delivery through oral routes for the new as well the existing active pharmaceutical ingredients. Research results and current market status showed promising potential in high patient compliance, enhanced absorption, avoidance of gastrointestinal or hepatic first pass metabolism, improved oral bioavailability of poorly water soluble drugs in HBL dosage form. For future development more scientifically rigorous and adequately studies are needed for better study of the bioequivalence, more relevant in vitro dissolution study, drug metabolism and drug-excipient interactions in the area of the hard boiled lozenges. Therefore exploration in this area will open a new gateway for development of hard boiled lozenges as powerful drug delivery technology.

\section{FUNDING}

No competing financial interests exist

\section{AUTHORS CONTRIBUTIONS}

All the authors have contributed equally.

\section{CONFLICT OF INTERESTS}

The authors declares no conflict of interest 


\section{REFERENCES}

1. Muhammad I, Sumeira R, Quratulain B, Muhammad IQ, Farhat J, Ahmed K. Orally disintegrating films: a modern expansion in drug delivery system. Saudi Pharm J 2016;24:537-46.

2. Hao Zhong, Ging Chan, Yuanjia Hu, Hao Hu, Defang Ouyang. A comprehensive map of FDA-approved pharmaceutical products. Pharmaceutics 2018;10:263.

3. Shoko N, Katsuhiko Y, Yuta A, Yukihiro I. Impact of physicochemical profiling for rational approach on drug discovery. Chem Pharm Bull 2013;61:1228-38.

4. Shripathy D, Addai RS, Gladson SA, Ravi GS, Srinivas H, Akhilesh D. Fast dissolving oral film of piroxicam: solubility enhancement by forming an inclusion complex with $\beta$-cyclodextrin, formulation and evaluation. J Young Pharm 2019;11:1-6.

5. Susan Hua. Advances in nanoparticulate drug delivery approaches for sublingual and buccal administration, front. Pharmacology 2019;10:128.

6. Deepika M, Aparna C, Prathima S. Formulation, evaluation and characterization of itraconazole lozenges. IOSR J Pharm Biol Sci 2004;9:86-94.

7. Rajesh K, Mahalaxmi R, Deepak K. Investigating the suitability of Isomalt and liquid glucose as sugar substitute in the formulation of salbutamol sulfate hard candy lozenges. J Chem Pharm Res 2011;3:69-75.

8. Stephen OM. A review on lozenges. AJMMS 2015;5:99-104.

9. Farrer F. Sprays and lozenges for sore throats. S Afr Fam Pract 2012;2:120-2.

10. Surbhi C. Review on lozenges for bacterial infection. IJRSFP 2017;7:16-22

11. Katharina T, Sina IG, Sandra K. Bioequivalence of locally acting lozenges: evaluation of critical in vivo parameters and first steps towards a bio-predictive in vitro test method. Eur J Pharm Biopharm 2018;123:71-83.

12. Grembecka M. Sugar alcohol-their role in the modern world of sweeteners: a review. Eur Food Res Tech 2015;241:1-14.

13. Hearnden V, Sankar V, Hull K. New developments and opportunities in oral mucosal drug delivery for local and systemic disease. Adv Drug Delivery Rev 2012;64:16-28.

14. Lam JK, Xu Y, Worsley A. Oral transmucosal drug delivery for pediatric use. Adv Drug Delivery Rev 2014;73:50-62.

15. Michael JR, Indiran P, Sevda S. Overview of oral mucosal delivery in a Michael JR, Sevda S, Indiran P. Advances in Delivery Science and Technology, Springer Boston, MA; 2015. p. $17-26$

16. Jensdottir T, Nauntofte B, Buchwald C, Bardow A. Effects of sucking acidic candy on whole-mouth saliva composition. Caries Res 2005;39:468-74.

17. Lee A, Wils D, Zumbe A, Storey DM. The comparative gastrointestinal responses of children and adults following consumption of sweets formulated with sucrose, isomalt and lycasin HBC. Eur J Clin Nutr 2002;56:755-64.

18. Michael MC, Feng Z, Michael AR, Sridhar T, Sampada BU, Sunil $\mathrm{KB}$, et al. Pharmaceutical applications of hot-melt extrusion: Part I. Drug Dev Ind Pharm 2007;33:909-26.

19. Mandel L, Carunchio MJ. Rampant caries from oral transmucosal fentanyl citrate lozenge abuse. J Am Dent Assoc 2011;142:406-9.

20. Collins AE, Deasy PB. Bioadhesive lozenge for the improved delivery of cetylpyridinium chloride. J Pharm Sci 1990;79:116-9.

21. Johnson D, Mead R, Kennelty K, Hahn D. Menthol cough drops: cause for concern? J Am Board Fam Med 2018;31:183-91.

22. Hemila H, Haukka J, Alho M, Vahtera J, Kivimaki M. Zinc acetate lozenges for the treatment of the common cold: a randomised controlled trial. Br Med J Open 2020;10:e031662.

23. Boyle $S$, Walters MR. Clinically significant interaction between warfarin and popular cough lozenges 'Fisherman's Friend'. Br Med J Case Rep 2011;28:bcr0920114791.

24. Rampurna PG. Soft gelatin capsules (Softgels). J Pharm Sci 2010;99:4107-48

25. Basavaraj S, Guru VB. Can formulation and drug delivery reduce attrition during drug discovery and development-review of feasibility, benefits and challenges. Acta Pharm Sin B 2014;4:3-17.
26. Leslie ZB, The role of BCS (Biopharmaceutics classification system) and BDDCS (Biopharmaceutics drug disposition classification system) in drug development. J Pharm Sci 2013;102:34-42.

27. Krithika K, Rajib G. Bioavailability enhancers of herbal origin: an overview. Asian Pac J Trop Biomed 2013;3:253-66.

28. Nannan G, Mengran G, Qiang F, Zhonggui H. Application of hot melt extrusion to enhance the dissolution and oral bioavailability of oleanolic acid. Asian J Pharm Sci 2017;12:66-72.

29. Ritesh AF, Tarique SM, Ajay RS, Purnima DA. Artemethersoluplus hot-melt extrudate solid dispersion systems for solubility and dissolution rate enhancement with amorphous state characteristics. J Pharm 2013. https://doi.org/ $10.1155 / 2013 / 151432$.

30. Eman AA, Soumyajit M, Abdulla A, Sultan A, Bader A, Xin F, et al. Hot melt extrusion as an approach to improve solubility, permeability, and oral absorption of a psychoactive natural product, piperine. J Pharm Pharmacol 2016;68:989-98.

31. Hong W, Huijeong J, Xuhong L. Drug delivery approaches in addressing clinical pharmacology-related issues: opportunities and challenges. AAPS 2015;17:1327-40.

32. Smith T, Kawa K, Eckl V, Johnson J. Sales of herbal dietary supplements in US increased $7.5 \%$ in 2015 consumers spent $\$ 6.92$ billion on herbal supplements in 2015, marking the 12th consecutive year of growth. Am Botanical Council Herbal Gram 2016;111:67-73.

33. Shephard A, Zybeshari S. Virucidal action of sore throat lozenges against respiratory viruses parainfluenza type 3 and cytomegalovirus. Antiviral Res 2015;123:158-62.

34. Tan TW, Chen BC, Tan HL, Chang CM. Effectiveness of amylmetacresol and 2,4-dichlorobenzyl alcohol throat lozenges in patients with acute sore throat due to upper respiratory tract infection: a systematic review protocol. JBI Database System Rev Implement Rep 2017;15:862-72.

35. Oxford JS, Lambkin R, Gibb I, Balasingam S, Chan C, Catchpole A. A throat lozenge containing amyl meta cresol and dichlorobenzyl alcohol has a direct virucidal effect on respiratory syncytial virus, influenza a and SARS-CoV. Antivir Chem Chemother 2005;16:129-34.

36. Wade AG, Morris C, Shephard A, Crawford GM, Goulder MA. A multicentre, randomised, double-blind, single-dose study assessing the efficacy of AMC/DCBA warm lozenge or AMC/DCBA cool lozenge in the relief of acute sore throat. BMC Fam Pract 2011;12:6.

37. Michael SC, Kenneth R, Ross WB, Maurice IM, Denis JM. Absorption of orally administered amphotericin B lozenges. $\mathrm{Br}$ J Clin Pharmac 1983;16:106-8.

38. Vries Hosper HG, Mulder NH, Sleijfer DT, Van Saene HK. The effect of amphotericin B lozenges on the presence and number of Candida cells in the oropharynx of neutropenic leukemia patients. Infection 1982;10:71-5.

39. Nagoba SN, Purushotham RK, Zakaullah S. Formulation of clotrimazole as lozenge tablet for improved delivery to oral thrush. JPBMS 2011;12:1-4

40. Neha D, Aparna C, Prathima S. Formulation and evaluation of medicated lozenges of albendazole for paediatric use. Asian J Biochem Pharm Res 2015;5:202-15.

41. Purushotham RK, Shivappa NN, Vishwanath R, Ayshiya SA, Zakaullah S, Ashok KC, et al. Medicated lollipops for the treatment of oral thrush in children. Int J Life Sci Btand Pharm Res 2012;1:95-102.

42. Michel C, Salvatico S, Belkhelfa H, Haddioui L, Roques C. Activity of Drill@lozenges on the main microorganisms responsible for upper respiratory tract infections. Eur Ann Otorhinolaryngol Head Neck Dis 2013;130:189-93.

43. Palm J, Fuchs K, Stammer H, Stimpfl AS, Milde J. Efficacy and safety of a triple active sore throat lozenge in the treatment of patients with acute pharyngitis: results of a multi-centre, randomised, placebo-controlled, double-blind, parallel-group trial (DoriPha). Int J Clin Pract 2018;72:e13272.

44. Caruso TJ, Prober CG, Gwaltney JM. Treatment of naturally acquired common colds with zinc: a structured review. Clin Infect Dis 2007;45:569-74. 
45. Garland ML, Hagmeyer KO. The role of zinc lozenges in treatment of the common cold. Ann Pharmacother 1998;32:63-9.

46. Eby GA. Zinc lozenges as cure for the common cold--a review and hypothesis. Med Hypotheses 2010;74:482-92.

47. Harri H, Elizabeth C. The effectiveness of high dose zinc acetate lozenges on various common cold symptoms: a meta-analysis. BMC Fam Pract 2015;16:24.

48. Mossad SB, Macknin ML, Medendorp SV, Mason P. Zinc gluconate lozenges for treating the common cold. A randomized, double-blind, placebo-controlled study. Ann Intern Med 1996;15125:81-8.

49. Ndindayino F, Vervaet C, Van den MG, Remon JP. Bioavailability of hydrochlorothiazide from isomalt-based moulded tablets. Int J Pharm 2002;246:199-202.

50. Mohd Yousuf Ali, Md Shamim Qureshi, Md Hamed, Byasabhusan Das, K Purushotham Rao. Design and evaluation of nimesulide lozenges for pediatrics. Res J Pharm Tech 2010;3:818-20.

51. Akansha Bhandarkar, Amit Alexander, Aditi Bhatt, Pankaj Sahu, Palak Agrawal, Tripti Banjare, et al. Formulation and evaluation of ascorbic acid lozenges for the treatment of oral ulcer. Res J Pharm Tech 2018;11:1307-12.

52. Campus G, Cocco F, Carta G, Cagetti MG, Simark Mattson C, Strohmenger L, et al. Effect of a daily dose of Lactobacillus brevis CD2 lozenges in high caries risk schoolchildren. Clin Oral Invest 2014;18:555-61.

53. Vito T, Stefano DC, Maurizio B, Antonella P. Use of lozenges containing Lactobacillus brevis CD2 in recurrent aphthous stomatitis: a double-blind placebo-controlled trial. Hindawi Publishing Corporation Ulcers 2011;439425:1-6.

54. Litty S, Nagarathna DV, Merline V. Probiotics in periodontal therapy. Int J Pharm Bio Sci 2015;6:242-50.

55. Teughels W, Durukan A, Ozcelik O, Pauwels M, Quirynen M, Haytac MC. Clinical and microbiological effects of Lactobacillus reuteri probiotics in the treatment of chronic periodontitis: a randomized placebo-controlled study. J Clin Periodontol 2013;40:1025-35.

56. Effects of lozenge containing lavender oil, extracts from hops, lemon balm and oat on electrical brain activity of volunteers. W Dimpfel, Pischel, R Lehnfeld. Eur J Med Res 2004;9:423-31.

57. Hina Rehman, Syed Adnan Ali, Safila Naveed, Khan Usmanghani. An interquartile relationship between polyherbal extract based lozenges linkus a phase IV comparative randomised control trial. Pak J Pharm Sci 2017;(3 Suppl):961-6.

58. Chu Hong Hu, Jian He, Randal Eckert, Xiao Yang Wu, Li-Na Li, Yan Tian, et al. Development and evaluation of a safe and effective sugar-free herbal lollipop that kills cavity-causing bacteria. Int J Oral Sci 2011;3:13-20.

59. MC Peters, JA Tallman, TM Braun, JJ Jacobson. Clinical reduction of S. mutans in pre-school children using a novel liquorice root extract lollipop: a pilot study. Eur Arch Paediatr Dent 2010;11:274-8.

60. Merve Erkmen Almaz, Isıl Saroglu Sonmez, Zeynep Okte, Aylin Akbay Oba. Efficacy of a sugar-free herbal lollipop for reducing salivary Streptococcus mutans levels: a randomized controlled trial. Clin Oral Investig 2017;21:839-45.

61. Yandi Chen, Melissa Agnello, Marcia Dinis Kenneth C Chien, Jing Wang, Wei Hu, Wenyuan Shi, et al. Lollipop containing Glycyrrhiza uralensis extract reduces streptococcus mutans colonization and maintains oral microbial diversity in Chinese preschool children. PLoS One 2019;14:e0221756.

62. Otis LB, Gregory F, Martin AJ, James MS. Development of a lozenge for oral transmucosal delivery of trans-resveratrol in humans: proof of concept. Plos One 2014;9:e90131.

63. Vinay KH, Aditee RS, Sindhu MG. Efficacy of curcumin in the treatment for oral submucous fibrosis-a randomized clinical trial. J Oral Maxillofac Pathol 2015;19:145-52.

64. Manayi A, Vazirian M, Saeidnia S. Echinacea purpurea: pharmacology, phytochemistry and analysis methods. Pharmacogn Rev 2015;9:63-72.

65. Schapowal A, Berger D, Klein P, Suter A. Echinacea/sage or chlorhexidine/lidocaine for treating acute sore throats: a randomized double-blind trial. Eur J Med Res 2009;14:406-12.

66. Guiotto P, Woelkart K, Grabnar I, Voinovich D, Perissutti B, Invernizzi S, et al. Pharmacokinetics and immunomodulatory effects of phytotherapeutic lozenges (bonbons) with Echinacea purpurea extract. Phytomed 2008;15:547-54.

67. Lone H, Gro CH, Hedvig N. Echinacea and Elderberry-should they be used against upper respiratory tract infections during pregnancy? Front Pharmacol 2014;5:31.

68. Alka D, Raman D, Yogesh KS. Exploration of phytochemicals found in Terminalia $s p$. and their antiretroviral activities. Pharmacogn Rev 2016;10:73-83.

69. Zakay Rones Z, Thom E, Wollan T, Wadstein J. Randomized study of the efficacy and safety of oral Elderberry extract in the treatment of influenza A and B virus infections. J Int Med Res 2004;32:132-40.

70. Tiralongo E, Wee SS, Lea R. Elderberry supplementation reduces cold duration and symptoms in air-travellers: a randomized, double-blind placebo-controlled clinical trial. Nutrients 2016;8:182.

71. Benbassat N, Kostova B, Nikolova I, Rachev D. Development and evaluation of novel lozenges containing marshmallow root extract. Pak J Pharm Sci 2013;26:1103-7.

72. White MR, Helmerhorst EJ, Ligtenberg A, Karpel M, Tecle T, Siqueira WL, et al. Multiple components contribute to ability of saliva to inhibit influenza viruses. Oral Microbiol Immunol 2009;24:1.

73. Malamud D, Abrams WR, Barber CA, Weissman D, Rehtanz M, Golub E. Antiviral activities in human saliva. Adv Dent Res 2011;23:34-7.

74. Fabian TK, Hermann P, Beck A, Fejerdy P, Fabian G. Salivary defense proteins: their network and role in innate and acquired oral immunity. Int J Mol Sci 2012;13:4295-320.

75. Luzzi R, Belcaro G, Pellegrini L, Cornelli U, Feragalli B, Dugall M. Phyto-relief CC: prevention of cold episodes. Control of signs/symptoms and complications. Minerva Gastroenterol Dietol; 2015.

76. Safinaz D, Soekanto SA, Sarwono AT. The effects of propolis honey candy consumption on myeloperoxidase activity in stimulated saliva. Int J Appl Pharm 2019;11:137-40.

77. Wijaya KM, Soekanto SA, Soedarsono N. Effect of honey propolis hard candy on lactoperoxidase activity in unstimulated saliva. Int J Appl Pharm 2019;11:103-5.

78. Khodijah K, Farida R, Soedarsono N. The effect of propolis extract and propolis candies on the growth of Aggregatibacter actinomycetemcomitans ATCC 43718. Asian J Pharm Clin Res 2017;10:26-9.

79. Anand K, Lakshmy R, Janakarajan VN, Ritvik A, Misra P, Pandey $\mathrm{RM}$, et al. Effect of consumption of micronutrient fortified candies on the iron and vitamin a status of children aged 3-6 y in rural Haryana. Indian Pediatr 2007;44:823-9.

80. Medeiros Neves B, Nemitz MC, Nathiely F, Fachel S, Teixeira HF. Recent patents concerning the use of nanotechnology-based delivery systems as skin penetration enhancers. Recent Pat Drug Delivery Formul 2019;13:192-202.

81. Kirsty Sawicka, Jasmine Takhar, Paul Marshall, Michael Fanfarillo. Production process for NSAID-containing lozenges, their compositions, their medicinal use. US20190307711A1. Reckitt Benckiser Healthcare UK Ltd; 2019.

82. John C Godfrey. Combination of zinc ions and vitamin $C$ and method of making. US6316008B1; 2018.

83. Bharat Pravinchandra Mehta, Rajen Dhirubhai Shah, Manoj Kantilal Patel, Parmeshwar B Bang. Nicotine containing formulation. J B Chemicals and Pharmaceuticals Ltd US20120244104A1; 2012.

84. Graham H. Brown, USPTO6082368, Nicotine candy cigarette; 2000.

85. Gian Carlo Santus, Nicotine lozenge, McNeil AB Pharmacia AB. US6280761B1; 2001.

86. Thomas S Ells, Joseph R Luber. Process for making a hard-candy based oral pharmaceutical lozenge containing an antacid. Johnson and Johnson Consumer Inc US5616340A; 1997.

87. Henryk Jakubowski. Teeth whitening candy with tartar removal and breath freshening properties, Jakubowski Henryk P, US20060210488A1; 2006.

88. Kaushik P, Kaushik D. Medicated chewing gums: recent patents and patented technology platforms. Recent Pat Drug Delivery Formul 2019;13:184-91. 
89. Laurence C Chow, Shozo Takagi, Gerald L Vogel. Anti-carious chewing gums, candies, gels, toothpastes and dentifrices. American Dental Association Health Foundation USPTO 5993786; 1999.

90. Brown Bruce A, Lane Philip A. Anaesthetic lozenges and method of preparing them. Beecham Inc. EP0001907A1; 1981.

91. Kay OD, Malcolm WK. Sweeteners and sugar alternatives in

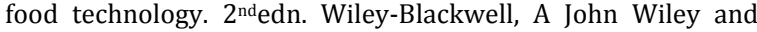
Sons, Ltd; 2012. p. 79.

92. Serpelloni Michel, Ribadeau Dumas Guillaume. Sugar based hard boiled sweets and process for it manufacture. US5601866; 1997.

93. Serpelloni Michel, Ribadeau Dumas Guillaume. Sugar-free hard boiled candy and process for its manufacture. US5629042; 1997.

94. Richard WH, Joachim HE, Randy H. Physico-chemical properties of sweeteners in confections. Confectionery Science and Technology; 2017. p. 39-67.

95. Leon Mentink, Michel Serpelloni. Sugar-free "hard candy" and process for its manufacture. US514701; 1994.

96. Ergun R, Lietha R, Hartel RW. Moisture and shelf life in sugar confections. Crit Rev Food Sci Nutr 2010;50:162-92.

97. Irena S, Jana C, Martin M. Crystals in Hard candies. Czech J Food Sci 2003;21:185-91

98. Richard WH, Roja E, Sarah V. Phase/State transitions of confectionery sweeteners: thermodynamic and kinetic aspects. Compr Rev Food Sci Food Saf 2011;10:17-32.

99. Wadesango L, Nxumalo N, Schellack N. An overview of throat lozenges and sprays in the management of pharyngitis at primary care level. S Afr Pharm J 2019;86:17-20.

100. Muhammad I, Sumeira R, Quratulain B, Muhammad IQ, Farhat J Ahmed K. Orally disintegrating films: a modern expansion in drug delivery system, Saudi Pharm J 2016;24:537-46.

101. Ells Thomas S, Luber Joseph R. Process for making a hardcandy based oral pharmaceutical lozenge containing an antacid. United States Patent,5,616,340; 1997.

102. Pinney John M, Henningfield, Jack E, Cone, Edward J. Chewing gums, lozenges, candies, tablets, liquids, and sprays for efficient delivery of medications and dietary supplements. United States Patent Application 20060073189; 2006.

103. Milchel S, Les B, Guillaaume RD. Sugar-based hard boiled sweet and process for its manufacture. USP5601866; 1997.

104. Ergun R, Lietha R, Hartel RW. Moisture and shelf life in sugar confections. Crit Rev Food Sci Nutr 2010;50:162-92.

105. Eckert C, Lutz C, Breitkreitz J, Woertz K. Quality control of oral herbal products by an electronic tongue-case study on sage lozenges. Sens Actuators B Chem 2011;156:204-12.

106. Md SU, Abdullah AM, Tanjuma T, Md A. Journal of in-process and finished products quality control tests for pharmaceutical tablets according to pharmacopoeias. J Chem Pharm Res 2015;7:180-5.

107. Uddin MS, Abdullah AM, MdSH, MdA, MdSS, Mamunur R, et al. In vitro quality evaluation of leading brands of ciprofloxacin tablets available in Bangladesh. BMC Res Notes 2017;10:185-94.

108. Milz B, Spangenberg B. A validated quantification of benzocaine in lozenges using TLC and a flatbed scanner. Chromatographia 2013;76:1307-13

109. Alqurshi A, Kumar Z, McDonald R, Strang J, Buanz A, Ahmed S, et al. Amorphous formulation and in vitro performance testing of instantly disintegrating buccal tablets for the emergency delivery of naloxone. Mol Pharmaceutics 2016;13:1688-98.

110. Pinto S, Manuela E, Pintado ME, Sarmento B. In vivo, in vitro and ex vivo assessment of buccal permeation of drugs from delivery systems. Expert Opin Drug Delivery 2019;17:33-48.
111. Wang S, Zuo A, Guo J. Types and evaluation of in vitro penetration models for buccal mucosal delivery. J Drug Delivery Sci $\quad$ Technol 2020 https://doi.org/10.1016/j.jddst.2020.102122

112. Yingyi M, David JM. Influence of electrostatic heteroaggregation of lipid droplets on their stability and digestibility under simulated gastrointestinal conditions. Food Funct 2012;3:1025-34.

113. Agrawal AM, Dudhedia MS, Zimny E. Hot melt extrusion: development of an amorphous solid dispersion for an insoluble drug from mini-scale to clinical scale. AAPS PharmSciTech 2016;17:133-47.

114. Patil H, Tiwari RV, Repka MA. Hot-melt extrusion: from theory to application in pharmaceutical formulation. AAPS PharmSciTech 2016;17:20-42.

115. Zhao X, Chen Q, Liu W, Li Y, Tang H, Liu X, et al. Codelivery of doxorubicin and curcumin with lipid nanoparticles results in improved efficacy of chemotherapy in liver cancer. Int J Nanomed 2015;10:257-70.

116. Mirza S, Miroshnyk I, Habib MJ, Brausch JF, Hussain MD. Enhanced dissolution and oral bioavailability of piroxicam formulations: modulating effect of phospholipids. Pharmaceutics 2010;2:339-50.

117. Hu L, Shi Y, Li JH, Gao N, Ji J, Niu F, et al. Enhancement of oral bioavailability of curcumin by a novel solid dispersion system. AAPS PharmSciTech 2015;16:1327-34.

118. Singh K, Sharma S. Development and characterization of orodispersible tablets of propranolol hydrochloride using calcium cross-linked cassia fistula gum and cross carmellose sodium. Int J Appl Pharm 2020;12:160-9.

119. Anita K, Matjaz K, Primoz S, Janez P. Potential of solid-state NMR and SEM in characterization of tablets of ibuprofen. Curr Pharma Anal 2015;11:124-30.

120. Rewanthwar SL, Lakshmi PK. Electronic tongue: an analytical gustatory tool. J Adv Pharm Technol Res 2012;3:3-8.

121. Abu Khalaf N, Zaid AN, Jaradat N, Alkilany A, Abu Rumaila B, Al Ramahi $\mathrm{R}$, et al. The taste of commercially available clarithromycin oral pharmaceutical suspensions in the palestinian market: electronic tongue and in vivo evaluation. Sensors 2018;18:E454.

122. Carolin E, Miriam P, Jurg R, Jorg B. Taste evaluation of multicomponent mixtures using a human taste panel, electronic taste sensing systems and HPLC. Sens Actuators B Chem 2013;182:294-9.

123. Carolin E, Christina L, Jorg B, Katharina W. Quality control of oral herbal products by an electronic tongue-case study on sage lozenges. Sens Actuators B Chem 2011;156:204-12.

124. Sharifzadeh A, Hajsharifi Shahreza M, Ghasemi Dehkordi P. Evaluation of microbial contamination and chemical qualities of cream-filled pastries in confectioneries of chaharmahal va bakhtiari province (Southwestern Iran). Osong Public Health Res Perspect 2016;7:346-50.

125. Carminati JD, Amorim Neto DP, Morishita KN, Takano LV, Olivier BA, Copetti MV, et al. Microbiological contamination in peanut confectionery processing plants. J Appl Microbiol 2016;121:1071-8

126. Govt. of India, Ministry of health and family welfare, Department of Ayurveda, Naturopathy, Unani, siddha (AYUSH), Part-II. Vol-III. $1^{\text {st }}$ Ed Ayurvedic pharmacopoeia of India: New Delhi; 2010.

127. Yuan X, Chapman RL, Wu Z. Analytical methods for heavy metals in herbal medicines. Phytochem Anal 2011;22:189-98. 